\title{
Studies on Mitotic Apparatus and Cytokinesis of Spermatocytes of Nine Species of Grasshopper
}

\author{
Ken-Ya Kawamura ${ }^{1}$ \\ Biological Department, Faculty of Science, Tokyo Metropolitan \\ University, Setagaya-ku, Tokyo, Japan
}

Received April 25, 1957

Since Bèlař's brilliant publication (1929) concerning the mitosis of grasshopper, Chorthippus, under both the living and fixed states, many investigations have been conducted with fixed materials. However, concerning the formation of the mitotic apparatus in the living cell, much has remained unknown, because the prophase in the grasshopper lasts usually long and requires a high degree of care in culture technique. An additional difficulty lies in the detection of the spindle body in the living cell. However, with the aid of the phase contrast microscopy, observation of both distribution and arrangement of mitochondria and detection of slight differences in the refractive indices between the spindle body and its surrounding cytoplasm make it possible to trace the course of the spindle formation.

In the living spermatocytes, Shimakura (1951-1956) has published detailed observations and cinematographs on the formation of spindle body and behavior of chromosomes, and the writer (1955) has published a preliminary report on the spindle formation. The present paper deals with comparative observations on the course of spindle formation and cytokinesis of primary spermatocytes in nine species of grasshopper.

The writer is under deep obligation to Dr. Katsuma Dan for his valuable advice and kind aid in the preparation of this manuscript.

\section{Materials and methods}

The following materials were used:

Family 1. Locustidae

Subfamily 1. Acridinae

1. Acrida turrita

2. Chloealtis genicularibus

3. Chortophaga viridifasciata

Subfamily 2. Locustinae

1. Oedaleus infernalis

Subfamily 3. Catantopinae

1 Present address: Department of Zoology and Entomology, University of Tennessee, Knoxville, Tennessee, U.S.A. 
1. Oxya velox

2. Oxya yezoensis

3. Miramella mikado

4. Podisma sapporense

Family 2. Acrydiidae

1. Acrydium japonicum

All observations were based on the primary spermatocytes derived from nymphal and adult specimens.

In order to trace the course of the spindle formation in the living state, testes were prepared by the method previously described (Kawamura, 1955) : By carefully cutting the follicle walls with a sharp knife, germ cells with a small amount of body fluid were extracted and placed upon a cover slip. The cover slip was then inverted over a depression slide and sealed with liquid paraffin. The procedure must be carried out swiftly and carefully.

Parallel observations were concurrently made by means of staining the mitotic apparatus with mercuric bromphenol blue (Mazia et al 1953).

As phase contrast setup, Zettnow's filter solution, periplan ocular $\times 10$ (Olympus), positive-medium contrast optics $\times 40$ (Olympus) and negativemedium contrast optics $\times 90$ (Tiyoda) were used at a temperature of approximately $23^{\circ} \mathrm{C}$.

The photomicrographs were taken with PM-6 (Olympus) by using Eastman Kodak $35 \mathrm{~mm}$ Plus X and Fuji $35 \mathrm{~mm}$ Neopan S film.

The drawings were made with the aid of a camera lucida at a magnifcation of approximately $\times 1000$.

\section{Observations in living materials}

1) Spindle formation: The course of spindle formation was traced successively in a single cell from diakinesis to metaphase.

In all these species the spindles were formed in the same manner as previously described (Kawamura 1955) in Acrydium japonicum (Figs. 1-7).

During the late diakinesis, a cytoplasmic spindle with well-developed asters was formed (Fig. 7, CS). The length of the cytoplasmic spindle was about $1 / 2$ cell diameter. The mitochondria were granular at the outset but they became thready, with the progress of stage, along the spindle contour and in between astral rays at either pole.

In Acrydium japonicum, two centrioles per pole of the cytoplasmic spindle were detected as the two dark dots by the negative contrast optics (Fig. 7).

The poles gradually separated from each other and approached the surface layer of the cell. At the same time, the intact nucleus with chromosomes clearly visible inside which now lay near the cytoplasmic spindle was gently drawn toward both poles. The nuclear membrane, thereafter, became indistinct 

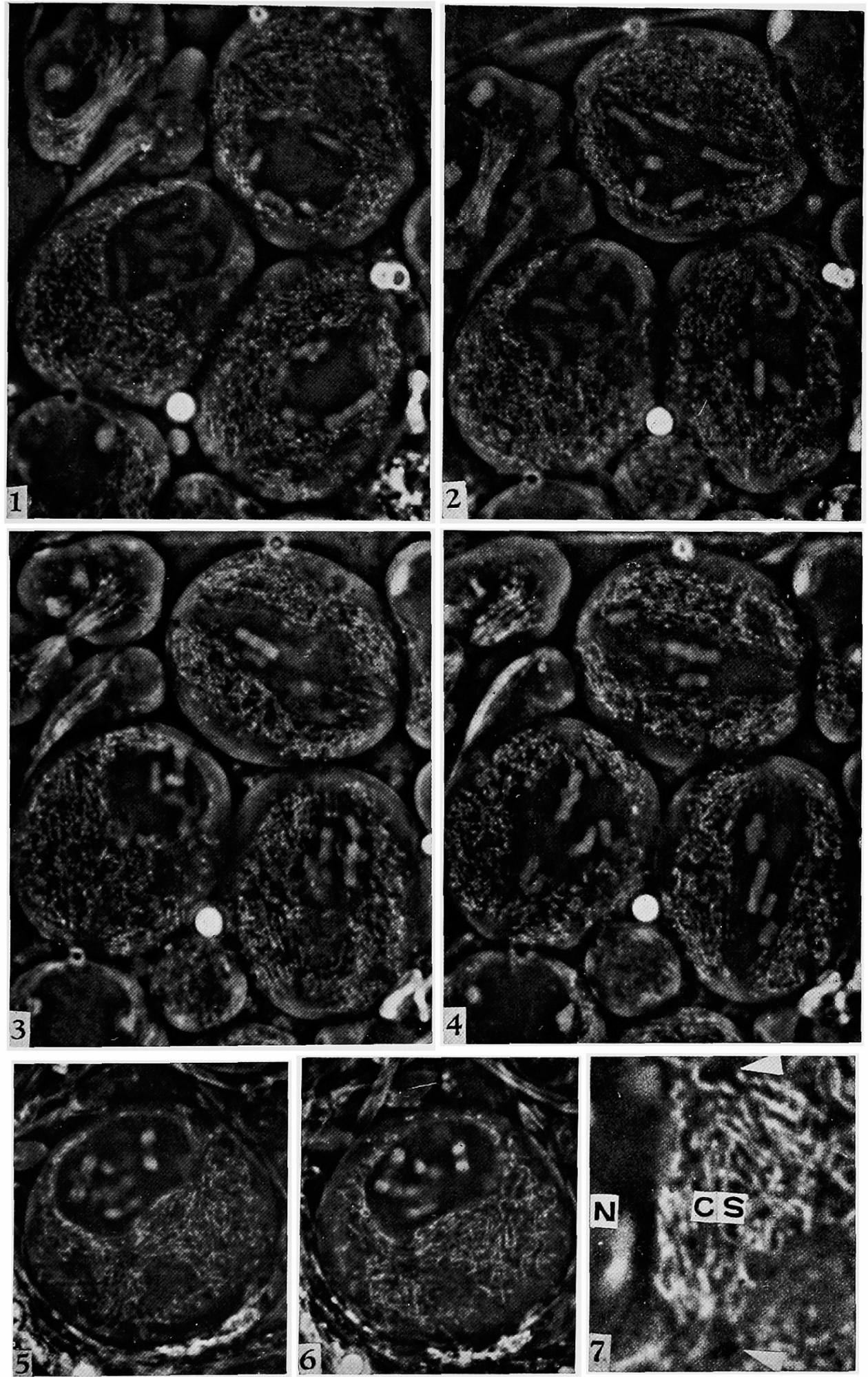

K. Kawamura: Mitotic Apparatus and Cytokinesis of Spermatocytes of Grasshopper 

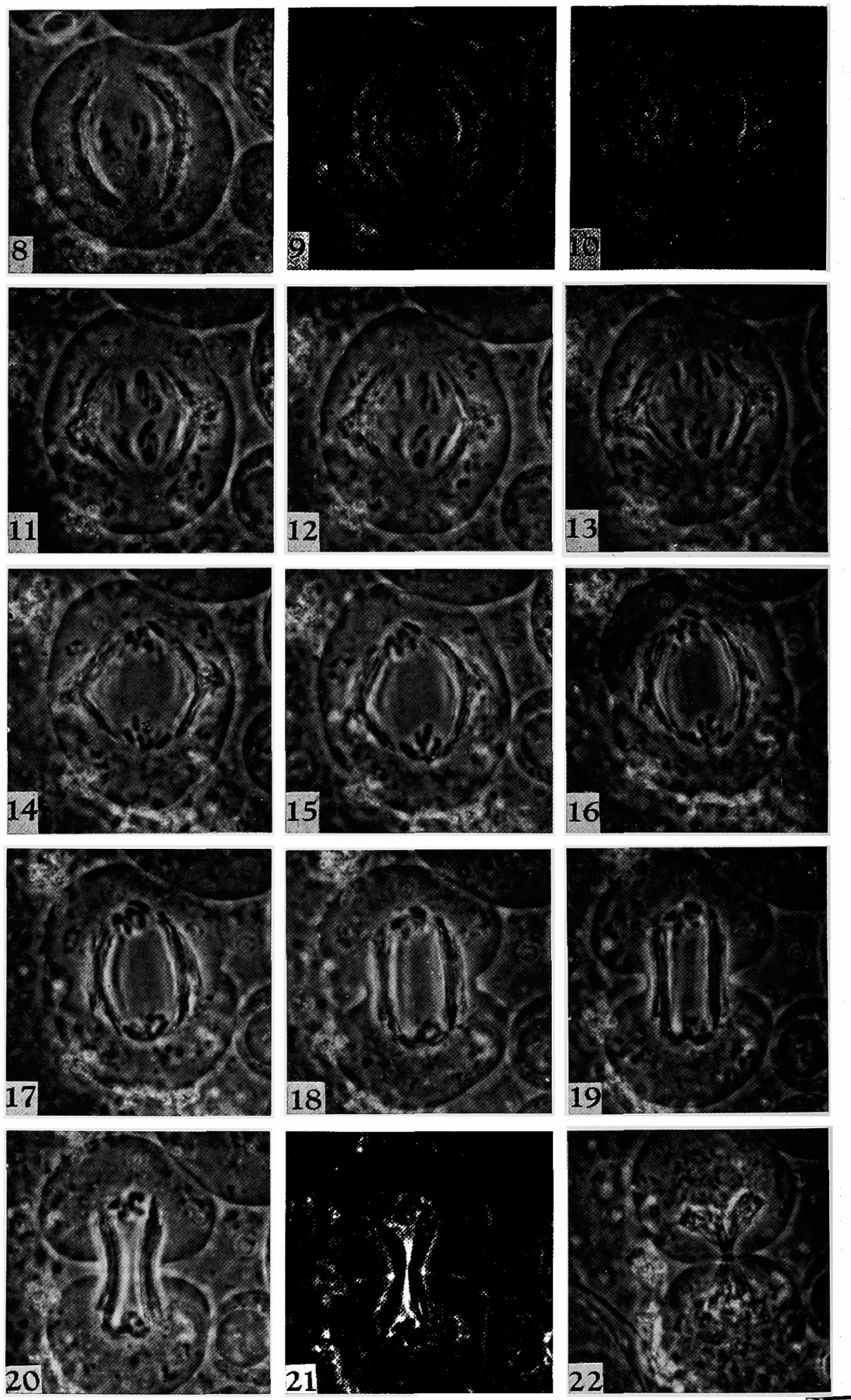

K. Kawamura: Mitotic Apparatus and Cytokinesis of Spermatocytes of Grasshopper 

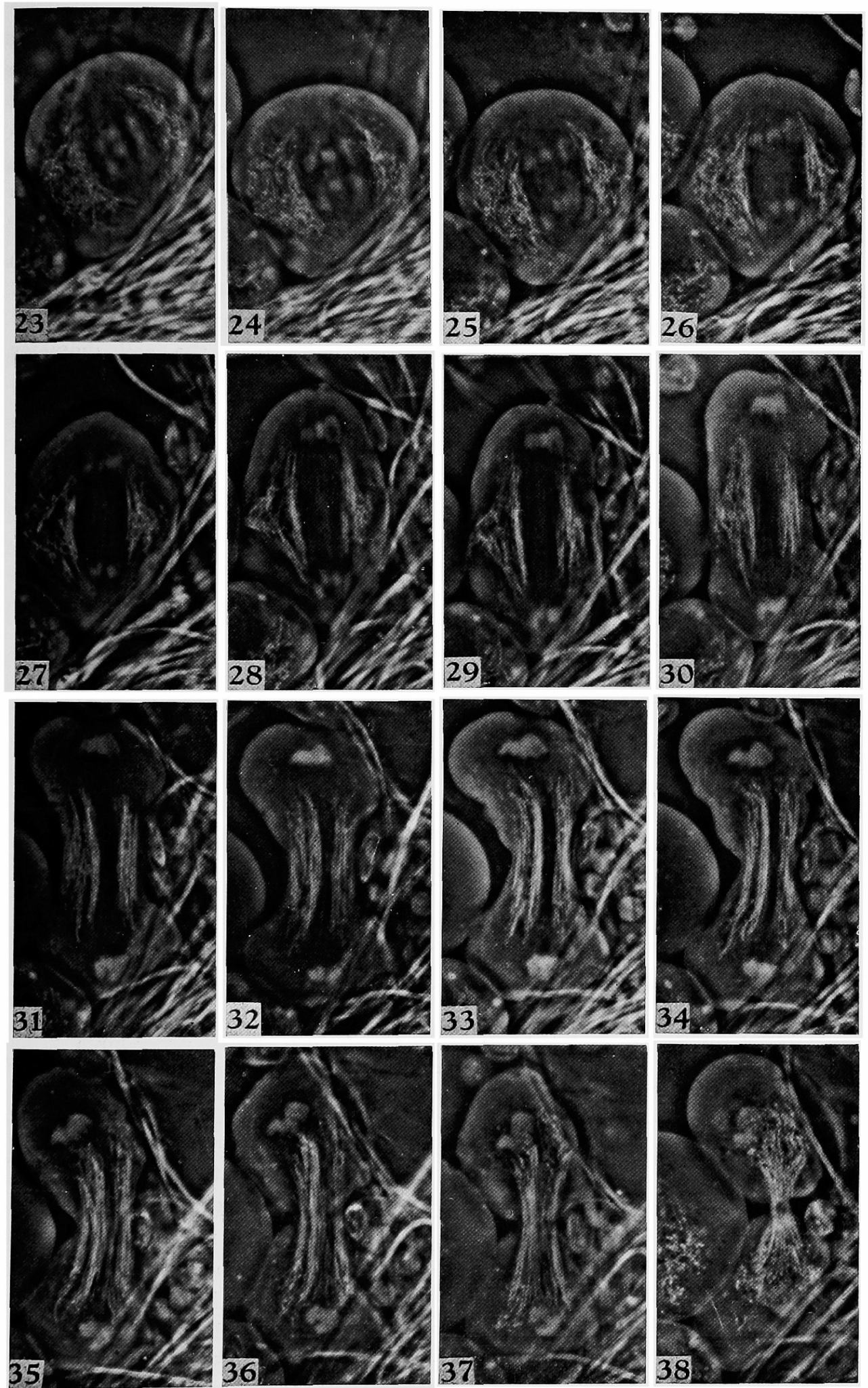

K. Kawamura: Mitotic Apparatus and Cytokinesis of Spermatocytes of Grasshopper 
along the area in contact with the cytoplasmic spindle. The mitochondria on the cytoplasmic spindle were pushed aside by the nuclear contents which then filled the inside of the cytoplasmic spindle and made it thicker. The metaphase spindle was thus formed. The chromosomes were finally gathered on the equatorial plane, and the cell entered into the metaphase.

Throughout the above process, the mitochondria were arranged along the contour of the spindle and astral rays.

2) Cytokinesis: The patterns of cleavage in most species are similar to those in the sea urchin egg; a furrow incising a cell into round daughter cells (Figs. 8-22). In Acrydium japonicum, however, a peculiar pattern of cleavage was observed (Figs. 23-38). During telophase, the cell diameter

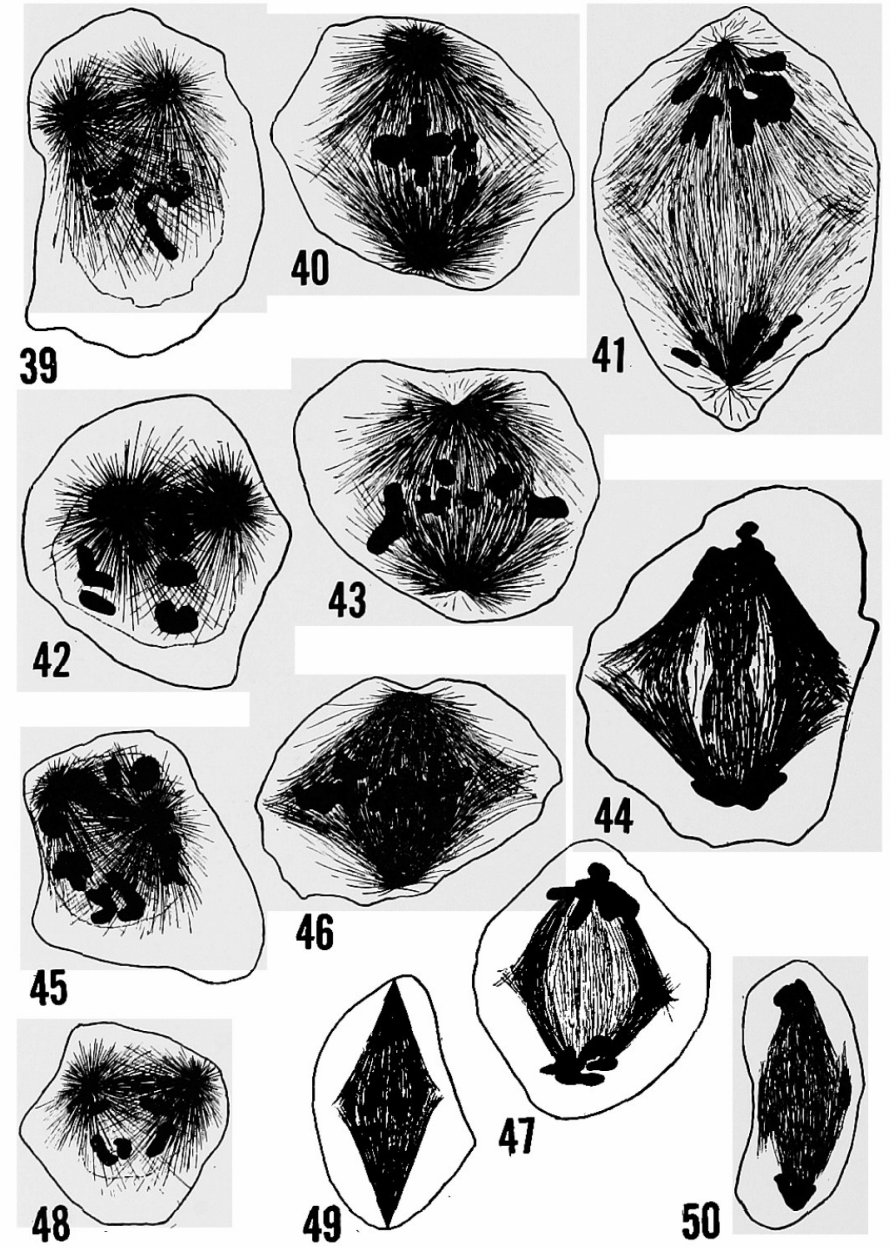

Figs. 39-50. Camera-lucida drawings showing primary spermatocytes stained by Hg-B.P.B. 39-41, Chortophaga viridifastiata; 42-44, Oedaleus infernalis; 45-47, Podisma sapporense; 48-50, Acrydium japonicum. $\times$ ca. 666 along the spindle axis elongated strikingly, and a wide furrow was formed initially with a relatively long interzonal region, and later, an incision was formed at the middle part of the interzonal region of the spindle.

\section{Observations in fixed} and stained materials

The testes were fixed by Allen's P.F.A. 3 , and sectioned in $15 \mu$ thickness by the standard paraffin method. The sections were stained with the following procedures by Mazia et al (1953). The preparations are immersed in the dye solution consisting of 10 grams of $\mathrm{HgCl}_{2}$ and $100 \mathrm{mg}$ of bromphenol blue per $100 \mathrm{ml}$ of water for 15 minutes and then washed for 20 minutes in $0.5 \%$ acetic acid, followed by rinsing in water for 15 minutes.

1) Prophase and prometaphase: At the late diakinesis, the cytoplasmic 
spindle was found in contact with the nucleus. Well-developed astral rays extended into the cytoplasm in three dimensional arrangements (Figs. 39, 42, 45 and 48 ).

The astral rays near the nucleus were bent along the nuclear contour, so that the nucleus was surrounded by a netwark of astral rays.

The cytoplasmic spindle, thereafter, lengthened to reach the cell surface layer, and, at the same time, the nuclear contents merged with the cytoplasmic spindle. The metaphase spindle was thus completed.

The above observations agree with these of the living state.

2) Metaphase: The appearances of mitotic apparatus at the metaphase are classified into three main types:

Type I: There are well-developed astral rays which are arranged in a star-like manner surrounding each of two spindle poles (Figs. 40 and 51). Acridinae belongs to this type.

Type II : Though developed astral rays are found in the cell, they are lacking at the polar regions (Figs. 43, 46 and 52). Locustinae and catantopinae belong to this type.

Tpye III : Spindle poles are directly anchored to the cell surface layer (Figs. 49 and 53). Acrydiidae belongs to this type.

Generally the area of the distribution of astral rays in the grasshopper is large in the prometaphase but it diminishes slightly in size during the metaphase and anaphase.

Astral rays spreading out from the two poles crossed each other in the equatorial region in the metaphase cell.

Mitochondrial arrangements observed in living cells perfectly correspond to the arrangements of the achromatic figure.
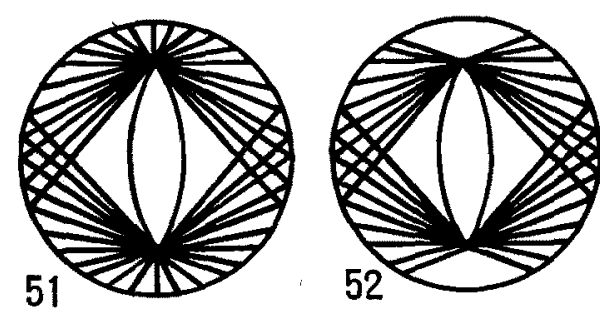

Figs. 51-53. Diagram showing three types of mitotic apparatus at metaphase. 51, Acridinae; 52, Locustinae and Catantopinae; 53, Acrydidae.

3) Anaphase and telophase : The distribution of astral rays is considerably diminished during anaphase and telophase, and astral rays are limited to the region near the spindle contour (Figs. 41, 44, 47 and 50).

\section{Remarks}

As the writer (1955) has reported in Acrydium japonicum, the cytoplasmic spindle definitely occurs outside of the nucleus in all the materials studied in this paper. The detailed observations and cinematographs by Shimakura (1951-1956) of the spindle formation in the spermatocytes of grasshopper, 
Chrysochraon japonicus, indicate, however, that a spindle-like body has been formed before the breakdown of the nuclear membrane by connection of astral rays from opposite poles, and that the complete form of the spindle is reached by the addition of the nuclear contents on its breakdown.

There are certain types of cell divisions in the salamander (Meves 1897) and in the mollusc Arion (Lams, 1910) where a miniature spindle is formed in the cytoplasm. This miniature spindle definitely occurs outside of the nucleus which gradually assumes metaphase proportion before the nuclear membrane breaks down. Such observations resemble strongly to the results in the present study. The writer has also found this to be the case in the nereid eggs (unpublished).

In accordance with these findings, the spindle body in animal cells may be said to have its precursor in the cytoplasm. On the contrary, Wada (1950) has proposed that the spindle body in the plant cell (Tradescantia) is derived solely from the nuclear contents, but general applicability of Wada's contention may need a reservation with respect to animal mitosis.

Nakahara (1952), Makino and Nakahara (1955) and Makino, Nakahara and Nakanishi (1956) have reported the behavior of mitochondria in the dividing spermatocytes of grasshopper, Podisma sapporense, and they have considered that the mitochondria played a significant part in the formation of the cleavage furrow. It is questionable to ascribe kinetic function to the mitochondrial arrangement on the sole base of its close association with the shape of the achromatic figure.

The asters in sea urchin eggs are small in metaphase and they grow considerably in size during anaphase (Swann 1951). The same is true with onion root tip (Östergren et al 1953). However, at a corresponding stage of the grasshopper spermatocytes, astral rays are bundled around spindle.

Nine species of Order Orthoptera can be classified into three types according to the form of the mitotic apparatus, and the fact that the three types are found in the different subfamilies of the order is significant in showing that taxonomic differences of the subfamilies are also reflected on the difference in the mode of the cell division.

In regard to cytokinesis the most of the species reveal much the same pattern as the sea urchin egg, except Acrydium japonicum. Although the mechanism involved are still unknown, a possibility is suggested that different modes of cytokinesis were derived from differences in the mitotic apparatus.

\section{Summary}

Comparative observations on the spindle formation and cytokinesis of the primary spermatocytes in nine species of grasshopper were carried out in the living and fixed materials.

The cytoplasmic precursor of the spindle body, three types of mitotic apparatus, and two types of the cleavage pattern were described and discussed. 


\section{Literature cited}

Bělař, K. 1929. Beiträge zur Kausalanalyse der Mitose. II. Untersuchungen an den Spermatocyten von Chorthippus (Stenobothrus) lineatus Panz. Roux'Arch. 118: 359-4ع4.

Kawamura, K. 1955. The course of spindle formation in the spermatocyte of the grasshopper, Acrydium japonicum, observed by phase microscopy. Cytologia 20: 4751.

Lams, H. 1910. Recherches sur l'oeuf d'Arion empiricorum (Fér). Acad. roy. Belg., Classe de Sciences 2: 1-170.

Makino, S. and Nakahara, H. 1955. Behavior of the mitochondria in relation to the division of the nuclear cytoplasmic bud in grasshopper spermatocytes. Chromosoma 7: $14-18$.

-, Nakahara, H., and Nakanishi, Y.H. 1956. $16 \mathrm{~mm}$ motion picture: Behavior of the mitochondria in relation to cytoplasmic division in grasshopper spermatocytes. Internatl. Symposia. Abstract pp. 103-104.

Mazia, D., Brewer, P. A. and Alfret, M. 1953. The cytochemical staining and measurement of protein with mercuric bromphenol blue. Biol. Bull, 104: 57-67.

Meves, F. 1897. Uber die Entwicklung der männlichen Geschlechtszellen von Salamandra maculosa. Arch. mikr. Anat. 48: 1-83.

Nakahara, H. 1952. Behavior of the mitochondria in cell division, with evidence concerning the kinetic function. Cytologia 17: 168-178.

Östergren, G., Koopmans, A. and Reitala, J. 1953. The occurrence of the amphiastral type of mitosis in higher plants and the influence of aminopyrin on mitosis. Botaniska Notiser 4: 417-419.

Shimakura, K. 1951. Mitotic spindle formation during the primary spermatocyte division in Acrididae. (In Japanese). Rec. 4th Ann. Meet., Hokkaido Branch, Zool. Soc Jap. p. 13.

- 1952. The behavior of the mitochondria during the primary spermatocyte division in Acrididae. I. (In Japanese). Zool. Mag. 61: 100.

- 1953. The behavior of the mitochondria during the primary spermatocyte division in Acrididae. II. (In Japanese). Zool. Mag. 62: 91.

- 1956. Some observations on the formation of mitotic spindle. (In Japanese). Zool. Mag. 65: 163.

- 1956. Spindle formation and chromosome transformation and movements during prometaphase I, as observed in living acridian speriratocytes. (In Japanese). Saibo Bunretsu (Cell Division), Iwanami and Co., Tokyo. pp. 37-56.

- 1956. $16 \mathrm{~mm}$ motion picture: Chromosome movements during spindle formation observed in the living spermatocytes of some grasshoppers. Internal. Genet. Symposia, Abstract p. 52 .

Swann, M. M. 1951. Protoplasmic structure and mitosis. I. The birefringence of the metaphase spindle and asters of the living sea-urchin egg. Jour. Expt1. Biol. 28: $417-433$.

- 1951. Protoplasmic structure and mitosis. II. The nature and cause of birefringence changes in the sea-urchin egg at anaphase. Jour. Exptl. Biol. 28: 434-444.

Wada, B. 1950. The mechanism of mitosis based on studies of the submicroscopic structure and of the living state of the Tradescantia cell. Cytologia 16: 1-26. 


\section{Explanation of Plates}

\section{Plate X}

Figs. 1-7. Photomicrographs of the primary spermatocytes of Acrydium japonicum taken with the aid of the phase microscope. $\times 900$. 1-4, successive series of intra-cellular changes during from diakinesis to metaphase; 5-5, late diakinesis-cell showing the formation of cytoplasmic spindle; 7 is the enlarging of Fig. 6, showing two centrioles per each pole of the cytoplasmic spindle. (CS, cytoplasmic spindle; N, nucleus; Arrows, centrioles).

\section{Plate XI}

Figs. 8-22. Successive series of cytogenesis in a single primary spermatocyte of Chloealtis genicularibus, followed from metaphase to telophase. $\times 430$.

\section{Plate XII}

Figs. 23-38. Successive series of cytokinesis in a single primary spermatocyte of Acrydium japonicum, followed from metaphase to telophase. $\times 900$. 